\title{
Medicated Chewing Gum Dosage Form
}

National Cancer Institute

\section{Source}

National Cancer Institute. Medicated Chewing Gum Dosage Form. NCI Thesaurus. Code C149648.

Solid sing le-dose preparation consisting of a basis, mainly composed of gums, intended to be chewed but not swallowed. The active substance(s) is (are) released in saliva by chewing. Medicated chewing gum is intended for local treatment of mouth diseases or systemic delivery after absorption through the oral mucosa or from the gastrointestinal tract. 